\title{
The interplay of reactive oxygen species and the epidermal growth factor receptor in tumor progression and drug resistance
}

\author{
Meng-Shih Weng ${ }^{1 \dagger}$, Jer-Hwa Chang ${ }^{2,3 \dagger}$, Wen-Yueh Hung ${ }^{4}$, Yi-Chieh Yang ${ }^{4,5}$ and Ming-Hsien Chien ${ }^{4,6^{*}}$ (D)
}

\begin{abstract}
Background: The epidermal growth factor receptor (EGFR) plays important roles in cell survival, growth, differentiation, and tumorigenesis. Dysregulation of the EGFR is a common mechanism in cancer progression especially in non-small cell lung cancer (NSCLC).

Main body: Suppression of the EGFR-mediated signaling pathway is used in cancer treatment. Furthermore, reactive oxygen species (ROS)-induced oxidative stress from mitochondrial dysfunction or NADPH oxidase (NOX) overactivation and ectopic expression of antioxidative enzymes were also indicated to be involved in EGFR-mediated tumor progression (proliferation, differentiation, migration, and invasion) and drug resistance (EGFR tyrosine kinase inhibitor (TKI)). The products of NOX, superoxide and hydrogen peroxide, are considered to be major types of ROS. ROS are not only toxic materials to cells but also signaling regulators of tumor progression. Oxidation of both the EGFR and downstream phosphatases by ROS enhances EGFR-mediated signaling and promotes tumor progression. This review primarily focuses on the recent literature with respect to the roles of the EGFR and ROS and correlations between ROS and the EGFR in tumor progression and EGFR TKI resistance.
\end{abstract}

Short conclusion: The evidence discussed in this article can serve as a basis for basic and clinical research to understand how to modulate ROS levels to control the development and drug resistance of cancers.

Keywords: Epidermal growth factor receptor, Reactive oxygen species, NADPH oxidase, Oxidation, Tumor progression, Drug resistance

\section{Background}

The epidermal growth factor (EGF) receptor (EGFR) is a receptor tyrosine (Tyr) kinase which is activated via extracellular ligand binding and induces downstream signaling pathways that regulate cell proliferation, differentiation, migration, and survival $[1,2]$. Mutation and/ or amplification of the EGFR gene leading to aberrant activation of downstream signaling pathways are critical mechanisms promoting tumorigenesis, especially in lung cancer [3, 4]. Lung cancers are classified into small-cell lung cancer (SCLC) and non-SCLC (NSCLC).

\footnotetext{
* Correspondence: mhchien1976@gmail.com

${ }^{\dagger}$ Equal contributors

${ }^{4}$ Graduate Institute of Clinical Medicine, College of Medicine, Taipei Medical University, 250 Wu-Hsing Street, Taipei 11031, Taiwan

${ }^{6}$ Department of Medical Education and Research, Wan Fang Hospital, Taipei Medical University, Taipei, Taiwan

Full list of author information is available at the end of the article
}

Pathologically, NSCLC accounts for $80 \%$ of lung cancer patients and is further categorized into adenocarcinomas, squamous cell carcinomas, and large-cell carcinomas based on the cytology [5]. Moreover, aberrant expression of the EGFR was found in $43 \%$ 86\% of NSCLC patients [6]. Although gefitinib, an EGFR Tyr kinase inhibitor (TKI), was used to treat NSCLC patients 13 years ago [7], highly metastatic properties and drug resistance during TKI therapy still cause poor prognoses of lung cancer patients [8,9]. Even now, the precise mechanism of resistance remains unclear, but it is well known that reactive oxygen species (ROS) are heavily involved in cancer initiation and regulation [10]. Exposure to environmental toxins, such as secondhand cigarette smoke and cooking smoke which are associated with oxidative stress formation, is an important mechanism participating in lung tumorigenesis through regulation of the EGFR-mediated signaling pathway [11, 12]. 
Therefore, understanding mechanisms between EGFR signaling pathways and oxidative stress-promoted lung tumorigenesis is necessary for lung cancer treatment and/or prevention.

Oxidative stress is defined as the overproduction of oxidants and/or a reduction in antioxidant defense abilities, which result in an imbalance of cellular oxidants and antioxidants [13]. Excessive production of oxidants comes from ROS/reactive nitrogen species (RNS) formation; these substances exhibit highly reactive activities toward cellular structural components, enzymes, and genetic materials leading to induction of inflammation, cell death, and tumorigenesis [14-16]. Furthermore, suppression of antioxidative enzyme expressions and activities by toxic materials also result in the emergence of oxidative stress. Basically, oxidative stress-regulated reductionoxidation reaction (redox) signaling pathways are well characterized as risk factors for cancer progression [15]. Blockade of oxidative stress-mediated signaling pathways is a good strategy for cancer treatment and prevention $[17,18]$. In this review, we summarized interactions of the EGFR and oxidative stress in tumor progression and TKI drug resistance.

\section{The role of the EGFR in tumor progression}

The EGFR belongs to the HER family of transmembrane receptor Tyr kinases and consists of four related receptors: EGFR/HER1/ErbB1, HER2/ErbB2/Neu, HER3/ ErbB3, and HER4/ErbB4 [19]. The EGFR is comprised of three domains: a glycosylated extracellular ligand-binding domain, a transmembrane domain, and an intercellular Tyr kinase domain. In normal physiological situations, EGFR activation is triggered by ligand binding and induction of EGFR homo- or heterodimerization. After receptor dimerization, Tyr residues in the Tyr kinase domain are autophosphorylated and activate downstream signaling pathways, such as Ras-Raf-extracellular signal-regulated kinase (ERK), phosphatidylinositol-3 kinase (PI3K)-Akt, and signal transducer and activator of transcription (STAT) signaling pathways, which regulate cell proliferation, migration, and survival [20]. However, aberrant expression of the EGFR via gene amplification, mutation, or protein overexpression results in dysregulation of EGFRmediated signaling pathways with subsequent tumorigenesis, especially in lung cancer [21-23]. Several anticancer agents as EGFR Tyr kinase inhibitors (TKIs) have been used in NSCLC patients with EGFR mutations [24]. However, resistance to EGFR TKIs through an EGFR T790 M mutation, MET amplification, and/or activation of other kinases has limited the application of clinical anticancer agents for NSCLC treatment [25]. Therefore, understanding EGFR-regulated signaling pathways or cross-talk of other molecular mechanisms with EGFR signaling pathways may provide a way to treat or prevent lung cancer.

\section{The role of oxidative stress in tumor progression}

"Oxidative stress" is defined as an imbalance between oxidant production and antioxidant defense systems. Overproduction of ROS/RNS by cellular metabolism or induction by exogenous sources triggers oxidative stress formation. ROS/RNS include free radicals and non-free radicals that have highly reactive activities with cellular components, such as lipids, proteins, and nucleic acids, and result in cellular dysfunction, gene mutations, tumor progression, and chemotherapeutic resistance [13, 26-29]. The majority of ROS/RNS are produced by mitochondrial metabolism, endoplasmic reticular stress, and peroxisomes. Reactions with intracellular enzymes, such as oxidase and oxygenase, also generate ROS/RNS [30, 31].

Mitochondrial ROS are metabolic byproducts and are produced from electron leakage during oxidative phosphorylation in the electron transport chain (ETC). Electrons escape from the ETC and bind to oxygen, with its subsequent reduction to superoxide anions $\left(\mathrm{O}_{2}{ }^{-}\right)$and induction of oxidative stress [31]. Complex I (NADH-ubiquinone oxidase) and complex III (ubiquinone-cytochrome c oxidoreductase) of the ETC are major sites of superoxide anion generation. It was demonstrated that complex I is the primary site of superoxide anion production, and superoxide anions generated from complex III are an activator of hypoxia-inducible factor (HIF) in both pathological and physiological conditions [31-33]. Higher concentrations of superoxide anions are observed in cancer cells than in normal cells because of mitochondrial dysfunction [31]. The oxidative stress induced by superoxide anions leads to destruction of mitochondria and genomic DNA followed by gene mutations. Furthermore, superoxide anions also disturb signaling pathways and result in cancer proliferation, survival, and malignancy [34]. In addition, superoxide anions are further catalyzed to hydrogen peroxide $\left(\mathrm{H}_{2} \mathrm{O}_{2}\right)$ by superoxide dismutase (SOD). Although hydrogen peroxide is not a free radical, it easily catalyzes free radical reactions and induces oxidative stress in living cells. For example, hydrogen peroxide can accept another electron from free $\mathrm{Fe}^{2+}$ by the Fenton reaction to become a hydroxyl radical $\left(\mathrm{OH}^{-}\right)$and cause DNA damage $[27,35]$. Hydrogen peroxide induces several types of DNA damage, including single- and double-stranded DNA breaks, DNA-protein cross links, and purine, pyrimidine, and deoxyribose modifications [36] (Fig. 1). Although changes in DNA are usually repaired by cells, persistent DNA damage causes replication errors, genomic instability, activation of oncogenes, and inactivation of tumor suppressor genes, and ultimately induces development of a variety of cancers [37]. Moreover, hydrogen peroxide induces oxidative stress and also regulates physiological signal transduction as a secondary messenger. ROS-mediated oxidation of cellular thiolcontaining compounds, such as protein cysteine (Cys) residues, is considered to play important roles in a wide 


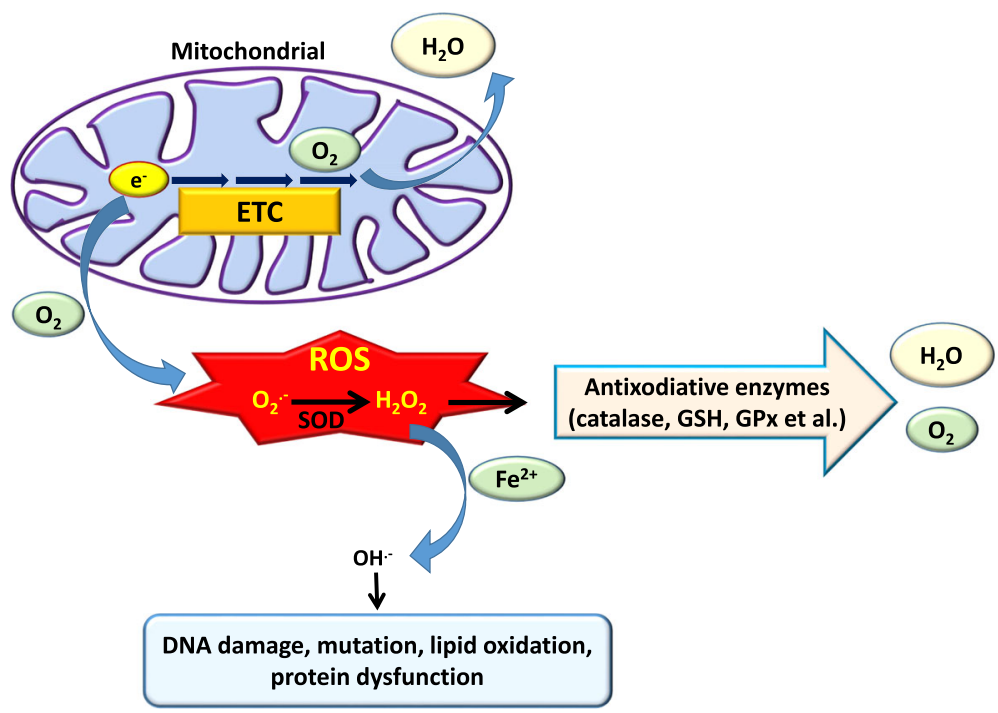

Fig. 1 Generation of reactive oxygen species (ROS) from mitochondria. $\mathrm{O}_{2}^{-}$is formed from molecular $\mathrm{O}_{2}$ by the gain of a single electron from electron leakage in the electron transport chain (ETC) of mitochondria. Superoxide dismutase (SOD) enzymes convert two superoxide molecules into hydrogen peroxide $\left(\mathrm{H}_{2} \mathrm{O}_{2}\right)$ and a water $\left(\mathrm{H}_{2} \mathrm{O}\right)$ molecule. Moreover, hydrogen peroxide is converted to the highly reactive ROS, the hydroxyl radical $\left(\mathrm{OH}^{-}\right)$, in the presence of iron $\left(\mathrm{Fe}^{2+}\right)$, which further causes damage to the cell structure including proteins, lipids, membranes, and DNA. Alternatively, hydrogen peroxide can be reduced to water by glutathione (GSH) peroxidase (GPx) or catalase

array of biological processes including signal transduction and regulation of the activities of enzymes, protein channels, and transcription factors [38]. For example, hydrogen peroxide was reported to modulate specific Cys residues within redox-sensitive proteins such as the EGFR [39-41]. Moreover, numerous signal molecules, such as the phosphatase and tensin homolog (PTEN), cyclin-dependent kinase (CDK), mitogen-activated protein kinases (MAPKs), and the transcription factor, activator protein (AP)-1, are also regulated by hydrogen peroxide [42-45] (Fig. 2).

The role of ROS in tumor angiogenesis

Angiogenesis is an essential step in tumorigenesis and metastasis. Until now, accumulating evidence suggested

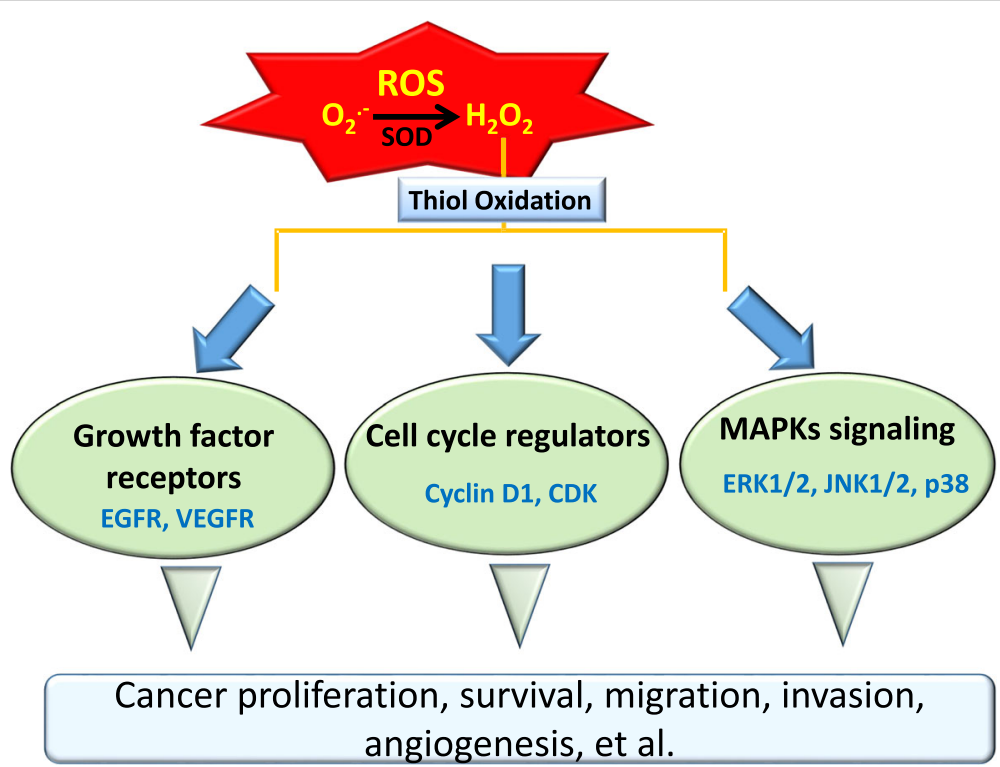

Fig. 2 Schematic of possible mechanisms of reactive oxygen species (ROS)-induced tumor progression. Excessive intracellular ROS in cancer cells can regulate growth factor receptors, cell cycle regulators, and mitogen-activated protein kinase (MAPK) signaling that contribute to cancer progression by promoting cell proliferation, survival, migration, invasion, and angiogenesis 
that ROS function as signaling molecules to mediate angiogenesis [46]. Numerous enzymatic systems capable of producing ROS were demonstrated, including cyclooxygenase (COX), nitric oxide synthase (NOS), the $\mathrm{NADPH}$ oxidase (NOX) family, etc. One of the major sources of ROS in endothelial cells (ECs) is NOX [46]. NOX family members are multiprotein complexes anchored to plasma membranes. Phagocyte oxidase was the first NOX identified, and it is required to defend against pathogenic infections of the respiratory system [47]. The NOX family has seven members, NOX1 5 and dual oxidase 1 and 2 (DUOX1 and -2) [48]. Generally, NOX shows relatively low activity under physiologic conditions. High NOX activity was shown to correlate with ROS production and tumorigenesis and can be induced by chemicals, growth factors, and inflammatory factors $[49,50]$. Different NOX members exhibit specific functions at both the tissue and cellular levels, and stimuli. For example, NOX1 is mainly expressed in the colon epithelium and is induced by angiotensin II [51], platelet-derived growth factor (PDGF) [52], and prostaglandins [53]. NOX4 has a wide tissue distribution, including ECs and the kidneys, and is activated by phorbol ester and insulin [54]. Moreover, expressions of NOX4 and NOX5 were shown to be higher in melanoma cells, prostate cancer cells, and lung cancer cells [55-57]. Recently, Han et al. further demonstrated that NOX activity and expression are associated with tumorigenesis of lung cancer, and inhibition of NOX function or messenger (m)RNA expression significantly blocks lung cancer formation and invasion [58]. Several NOX enzymes, including NOX1, NOX2, NOX4, and NOX5, as well as cytosolic regulatory subunits, including $\mathrm{p} 47^{\text {phox }}, \mathrm{p} 67^{\text {phox }}$, and Rac1, were shown to be involved in ROS production in ECs [46]. According to the type of ROS generated, NOX family members can be further divided into superoxide generators (NOX1 3 and NOX5) and hydrogen peroxide producers (NOX4 and DUOX1 and-2) [48]. Previously, Arbiser et al. demonstrated that NOX-mediated upregulation of hydrogen peroxide induces vascular endothelial growth factor (VEGF) and its receptor (VEGFR-2) expressions and matrix metalloproteinase (MMP) activities, markers of the angiogenic switch, thereby promoting angiogenesis and expansion of tumors [59]. In addition, several other angiogenesis-related transcription factors and genes are also regulated by ROS. For example, HIF-1, redox factor (Ref)-1, nuclear factor (NF) $-\mathrm{kB}$, and AP-1 are redox-sensitive transcription factors, and COX-2, plasminogen activator inhibitor (PAI)-1, and urokinase plasminogen activator (uPA) are redox-sensitive genes [46]. In contrast to ROS-induced angiogenesis-related transcription factors and gene expressions, NOX is also activated by numerous stimuli including the VEGF, EGF, angiopoietin (Ang)-1, urotensin (U)-II, shear stress, and hypoxia in ECs [60, 61]. VEGF can activate Rac1depedent NOX to induce ROS production in ECs [62]. Furthermore, ROS-induced HIF expression shows positive feedback regulation on NOX expression in ECs [61] (Fig. 3).

\section{Interaction between the EGFR and oxidative stress in tumor progression}

Twenty years ago, Gamou and Shimizu first identified the connection between hydrogen peroxide and the EGFR. They treated human squamous carcinoma NA cells with hydrogen peroxide $(0 \sim 1 \mathrm{mM})$ and found that hydrogen peroxide enhanced EGFR phosphorylation. They found a discrepancy between EGF-induced EGFR activation and hydrogen peroxide-induced EGFR activation, in that hydrogen peroxide might preferentially induce EGFR Tyr phosphorylation, whereas EGF stimulation would trigger both serine/threonine (Ser/ Thr) and Tyr receptor phosphorylation [63]. Inhibition of Cys-dependent protein Tyr phosphatases (PTPs) by hydrogen peroxide may be a critical mechanism inducing EGFR Tyr phosphorylation [64]. In addition, the intracellular kinase domain of the EGFR contains six Cys residues, and Cys797 is located in the ATP-binding pocket and is preferentially targeted by endogenous hydrogen peroxide [65]. Cys797 is a specific site of oxidation, and increased EGFR kinase activity after Cys797 oxidation was observed $[66,67]$. Therefore, oxidation of specific residues in PTPs and/or the EGFR contribute to increased downstream signaling. Moreover, Goldkorn et al. also demonstrated that exogenous hydrogen peroxide stimulated EGFR Tyr kinase activity and increased the receptor half-life in NSCLC cells. They found that the half-life of the EGFR was about $8 \mathrm{~h}$ when treated with EGF, whereas hydrogen peroxide treatment prolonged the half-life of the EGFR to $18 \mathrm{~h}$. According to those data, the authors suggested that EGF- and hydrogen peroxide-induced EGFR activation may have separate functions and represent an alternate mechanism by which EGFR signaling can be tuned in parallel to treatment with its native ligand [68].

In addition to the overall increase in Tyr autophosphorylation by the EGFR, hydrogen peroxide can also be a secondary messenger to regulate signal transduction [69]. After EGF stimulation, the EGFR transmits activation signals to downstream signaling cascades, including the Ras/MAPK and PI3K/Akt pathways. Hydrogen peroxide modulates the Src homology 2 domain-containing (SHC) protein, growth factor receptor-bound protein 2 (Grb2), and guanine nucleotide exchange protein (SOS) to form the SHC-Grb2-SOS complex [70, 71]. Once the SHC-Grb2-SOS complex is associated with the EGFR, the SOS promotes the exchange of GDP for GTP on 


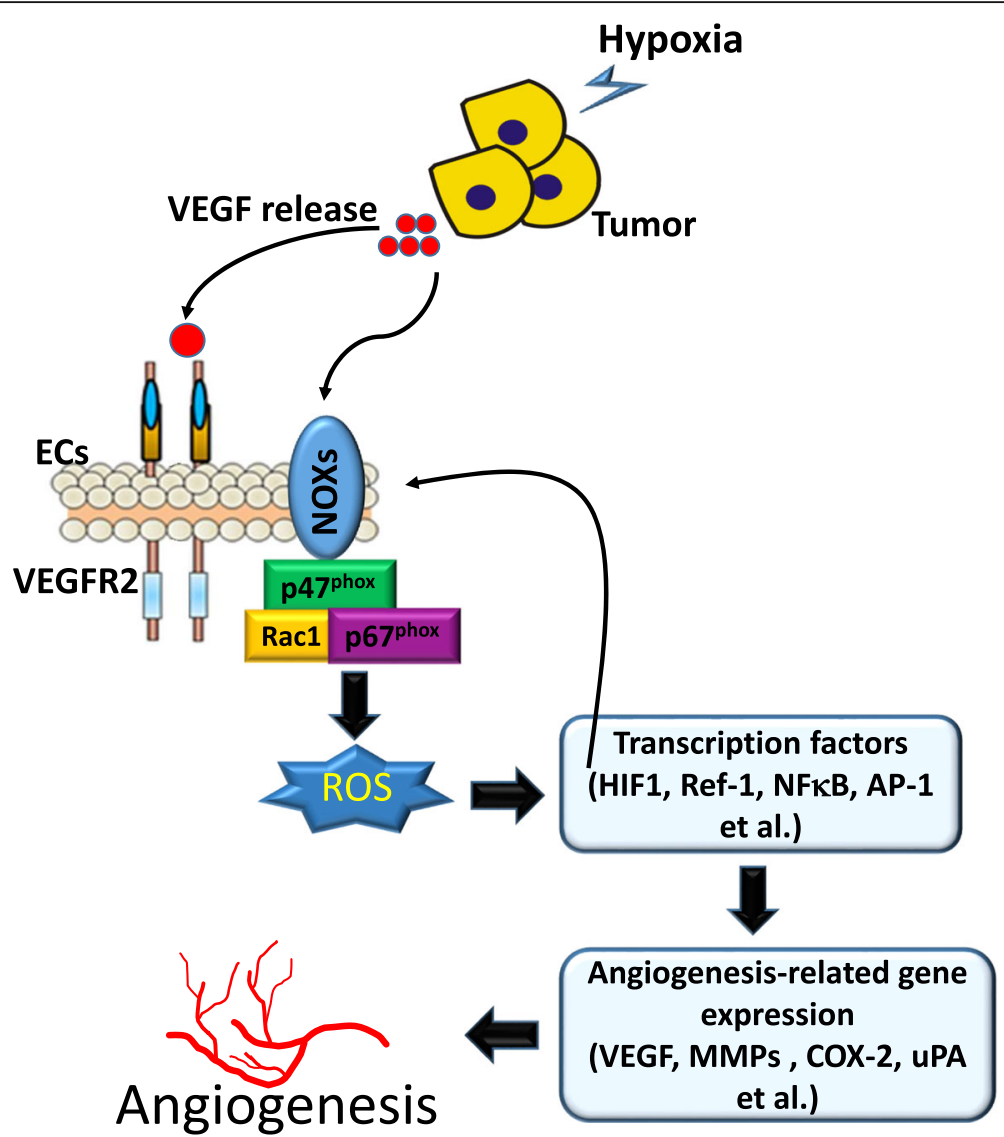

Fig. 3 Roles of NADPH oxidase (NOX)-derived reactive oxygen species (ROS) in regulating angiogenesis. Hypoxia induces vascular endothelial growth factor (VEGF) production from tumor cells which stimulates NOXs to produce ROS, thereby inducing downstream redox signaling events including expressions of various redox-sensitive transcriptional factors (hypoxia-inducible factor (HIF)-1, redox factor (Ref)-1, nuclear factor (NF)-KB, and activator protein (AP)-1) and genes (VEGF, matrix metalloproteinases (MMPs), cyclooxygenase (COX)-2, and urokinase plasminogen activator (UPA)), which are involved in angiogenesis. ECs, endothelial cells

Ras, a small G protein. Complexes that contain the SHC protein were reported to be better at activating RAS than those without it [72]. GTP-bound active Ras can then bind with and activate the MAPK kinase kinase (MAPKKK) protein, Raf. Raf can further induce the phosphorylation of a Ser residue in the activation loop of MEK (MAPKK) [73]. Thereafter, activated MEK1/2 phosphorylates the MAPK protein, extracellular signalregulated kinase (ERK), on adjacent Thr and Tyr residues, separated by a glutamic acid residue, at the activation loop. Eventually, this pathway controls various cellular processes of cancer including growth, proliferation, differentiation, migration, and inhibition of apoptosis [74, 75] (Fig. 4).

The PI3K-Akt-mammalian target of rapamycin (mTOR) signaling cascade is a signal transduction pathway involved in regulating multiple cellular functions including proliferation, survival, cell size, migration, and invasion. In cancer, this pathway is often hyperactivated due to activating mutations of EGFR family members. Activation of the EGFR leads to recruitment and activation of Akt at plasma membranes by activating the PI3K-induced formation of phosphatidylinositol-3,4,5-triphosphate ( $\left.\mathrm{PIP}_{3}\right)$ [76]. The signaling potential of $\mathrm{PIP}_{3}$ is controlled by the PI3K antagonist, PTEN, which dephosphorylates and limits the activity of $\mathrm{PIP}_{3}$ and is frequently inactivated in cancer [77]. In addition, it was found that increased endogenous hydrogen peroxide through overexpression of NOX1 elevates intracellular $\mathrm{PIP}_{3}$ concentrations and promotes the PI3K/Akt signaling pathway due to inhibition of PTEN activity [78, 79]. Hydrogen peroxide inhibits phosphatase activity by triggering the formation of a disulfide bond between the catalytic Cys, Cys124, and the closely aligned Cys, Cys71 [80] (Fig. 4). Akt is a Ser-Thr protein kinase which exists in three isoforms, including ubiquitously expressed Akt1 and Akt2, and Akt3, which is predominantly expressed in the brain, kidneys, and heart 


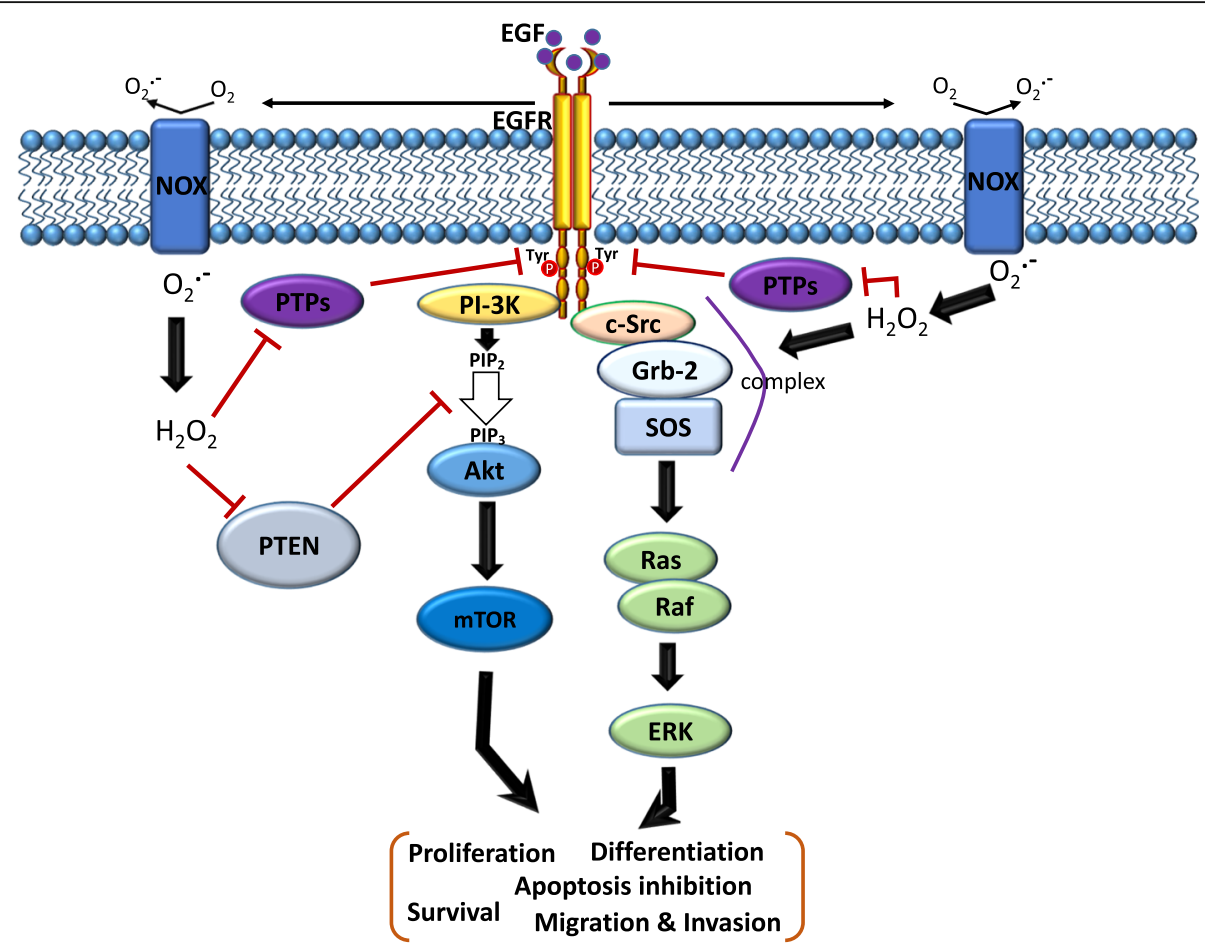

Fig. 4 Schematic of the cross-talk between the epidermal growth factor (EGF)-EGF receptor (EGFR) axis and NADPH oxidase (NOX)-mediated reactive oxygen species (ROS) signaling pathways. The binding of EGF to the EGFR induces receptor dimerization and then autophosphorylation of tyrosine (Tyr) residues (red circles) in its cytoplasmic domain. These phosphorylated Tyr residues serve as docking sites for associated proteins which activate multiple pathways. In particular, the Ras/Raf/mitogen-activated protein kinase (MAPK) and phosphatidylinositol-3-kinase (PI3K)/Akt pathways downstream of the EGFR play critical roles in cell migration, invasion, proliferation, and survival. Moreover, the EGF-EGFR axis also induces NOX-mediated hydrogen peroxide production, and hydrogen peroxide can diffuse across the membrane to reach the intracellular cytosol. Transient increases in hydrogen peroxide induce oxidation of reduction-oxidation reaction (redox) targets such as phosphatase and tensin homolog (PTEN) to promote Akt activation, protein tyrosine (Tyr) phosphatases (PTPs) to enhance EGFR Tyr phosphorylation, or complex formation of SHC-Grb2-SOS with the EGFR to activate Ras/MAPK signaling. Grb-2, growth factor receptor-bound protein 2; SOS, guanine nucleotide exchange protein

[81]. Similar to PTEN, Akt2 can form an intracellular disulfide bond between two Cys molecules in the activation loop, which inhibits kinase activity [82]. Elimination of hydrogen peroxide by overexpression of antioxidant enzymes, such as glutaredoxin, sustains Akt phosphorylation and inhibition of apoptosis through protecting Akt against hydrogen peroxide-induced oxidation [83].

In contrast to hydrogen peroxide-induced EGFR activation, the addition of EGF to human epidermoid carcinoma A431 cells, which highly express the EGFR, leads to increased levels of intracellular ROS, especially hydrogen peroxide [64] (Fig. 4). Moreover, EGFinduced Tyr phosphorylation of phospholipase $C_{\gamma} 1$ (PLC $\gamma 1$ ), a well-known physiological substrate of the EGFR, is inhibited through elimination of ROS by catalase, suggesting that inhibition of Cys-dependent PTPs by hydrogen peroxide might be required to increase the Tyr phosphorylation of PLC $\gamma 1$ [64]. Until now, the precise molecular mechanisms of EGFinduced hydrogen peroxide generation are still not very clear.
The role of ROS in drug resistance of EGFR TKIs

Targeting the EGFR is a strategy for lung cancer treatment and prevention. However, drug resistance has emerged after chronic treatment with EGFR TKIs. It was reported that high basal ROS levels were observed in TKI-resistant NSCLC cell lines, and high NOX2 expression-mediated ROS production was associated with poor patient survival in clinical lung tumors [11]. A previous report indicated that oxidation of Cys797 of the EGFR could promote binding of the EGFR to NOX2 and further enhance ROS generation and EGFR activation [40, 66]. Moreover, EGFR-sensitive NSCLC cell lines exposed to ROS resulted in TKI resistance by abnormal EGFR phosphorylation and disruption of the canonical dimer structure of the EGFR [84, 85]. Furthermore, cigarette smoke extract was reported to induce EGFR TKI resistance via promoting ROS generation and EGFR signaling pathway activation $[85,86]$. In addition to NSCLC, ROS were also reported to play a critical role in mediating EGFR-TKI resistance in breast cancer cells [87]. Treatment of lung cancer cells with an EGFR-TKI 
was reported to increase ROS concentrations or Src activation and further induce epithelial-to-mesenchymal transition (EMT)-mediated drug resistance $[88,89]$. The EMT was reported to play a critical role in cancer metastasis and EGFR-TKI resistance [90]. Src activation was indicated to regulate proliferation and the EMT in lung cancer [91]. Moreover, Src is one of the major downstream target molecules of ROS [92]. Taken together, interactions among ROS, Src, EGFR signaling, and the EMT are very important to EGFR-TKI resistance and might serve as druggable targets to overcome resistance to EGFR-TKIs. For example, combination treatment with TKIs and ROS scavengers partially reversed the EMT and restored mitochondrial functions $[93,94]$. Accordingly, antioxidants could potentially provide therapeutic benefits by attenuating ROS-mediated tumor progression and TKI resistance. Although it is understood that antioxidants are beneficial in preventing NSCLC and other cancers [95-97], several clinical trials recently reported that dietary supplementation with antioxidants such as vitamin $\mathrm{A}$, vitamin $\mathrm{C}$, vitamin $\mathrm{E}$, retinol, and beta-carotene did not significantly influence $[98,99]$ or further heightened [100-102] the risk of certain cancer types such as prostate, pancreas, head and neck, and lung cancers. The contradictory effects of antioxidants on cancers might be due to levels of ROS production by tumor cells.

\section{Low and high ROS concentrations play contrary roles in tumor progression and drug resistance}

Chronic exposure to low ROS levels can effectively regulate mitosis, cell survival, cell growth, cell proliferation, and angiogenesis in cancers [103] Moreover, tumorinitiating cells (TICs) play an important role responsible for TKI and chemotherapeutic resistance in tumors [104], which maintain lower ROS levels than their moremature progeny owing to expressions of ROSscavenging molecules and mechanisms such as CD13, glutathione synthetase, glutamate cysteine ligase, nuclear factor-erythroid 2-related factor 2 (NRF2), and Forkhead box protein O1 (FOXO1)-mediated upregulation of SOD and catalase [17, 105-107]. Overexpression of drug efflux pumps in TICs is an important mechanism for drug resistance of TICs. Low concentrations of ROS in TICs were reported to induce upregulation of the drug efflux pump, P-glycoprotein (P-gp), which promoted acquisition of the multidrug resistance (MDR) phenotype $[108,109]$. Overexpression of P-gp was found with a low concentration $(1 \mu \mathrm{M})$ of hydrogen peroxide treatment; however, a high concentration $(10 \mu \mathrm{M})$ of hydrogen peroxide treatment suppressed the expression of P-gp in cells, hence producing a concentrationdependent contribution of ROS to P-gp-mediated drug resistance [110]. Patients with TKI-resistant NSCLC and an additional EGFR ${ }^{\mathrm{T} 790 \mathrm{M}}$ mutation represent almost half of all NSCLC TKI-resistant cases [111]. In a basal condition of H1975 NSCLC cells harboring the EGFR ${ }^{\mathrm{T} 790 \mathrm{M}}$ mutant, activated $\mathrm{EGFR}^{\mathrm{T} 790 \mathrm{M}}$ can induce NOX2mediated upregulation of ROS, further oxidizing Cys797 and methionine (Met)790 of the EGFR. Mild oxidation of Met790 can be physiologically reversed to the reduced form by the Met reductase, Met reductase A (MsrA), and oxidation of Cys797 on EGFR ${ }^{\mathrm{T} 790 \mathrm{M}}$ can further induce EGFR activation and cell proliferation $[11,66]$ (Fig. 5a). In contrast to low ROS levels, high ROS levels were shown to have toxic effects on cancer cells, by triggering several signal transduction pathways to induce cell cycle arrest and cell death and overcome TKI resistance $[11,15]$. For example, apoptosis signal-regulating kinase 1 (ASK1) acts as a redox sensor by activating JNK and p38 MAPK to induce apoptosis upon excessive ROS [112]. ROS-induced p38/JNK MAPK signaling can downregulate cyclins and induce CDK inhibitors resulting in cell cycle arrest [113]. In EGFR-TKI-resistant H1975 cells, Leung et al. indicated that sanguinarine, a powerful ROS producer, caused excessive accumulation of ROS by activating NOX3 to further inactivate MsrA and induce overoxidation of $\mathrm{EGFR}^{\mathrm{T} 790 \mathrm{M}}$, and finally mediate EGFR degradation and cell death. This finding indicated that induction of NOX3 activation and Met790 oxidation is a novel target for treating NSCLC patients with the EGFR ${ }^{\mathrm{T} 790 \mathrm{M}}$ mutation [11] (Fig. 5b). Moreover, overproduction of ROS through the simultaneous induction of superoxide and hydrogen peroxide was reported to synergistically induce the death of NSCLC cells [114]. Taken together, the information detailed above indicates that maintaining endogenous and induced ROS at moderate levels can mediate drug resistance and allow tumor cells to survive treatment, resulting in both stemness and cancer-initiating capabilities.

\section{Summary and concluding remarks}

An imbalance of oxidants and antioxidants decides ROS levels in tissues. ROS-induced oxidative stress is a double-edged sword in cancers. Moderate ROS levels play positive roles in cancer such as promoting inflammation, tumor progression, and drug resistance. In contrast, excessive ROS can induce negative responses such as growth inhibition or death of cancer cells [115]. Mitochondrial dysfunction is the major mechanism inducing oxidative stress. Furthermore, dysregulation of enzymatic reactions also produces ROS in cancer cells, such as NOX. Reversing mitochondrial function and antioxidative enzyme activity can suppress ROS-mediated tumor progression. ROS not only function as mediators of the EGF/EGFR signaling pathway, but also as regulators of the oxidation status and activation of the EGFR protein. Oxidation 

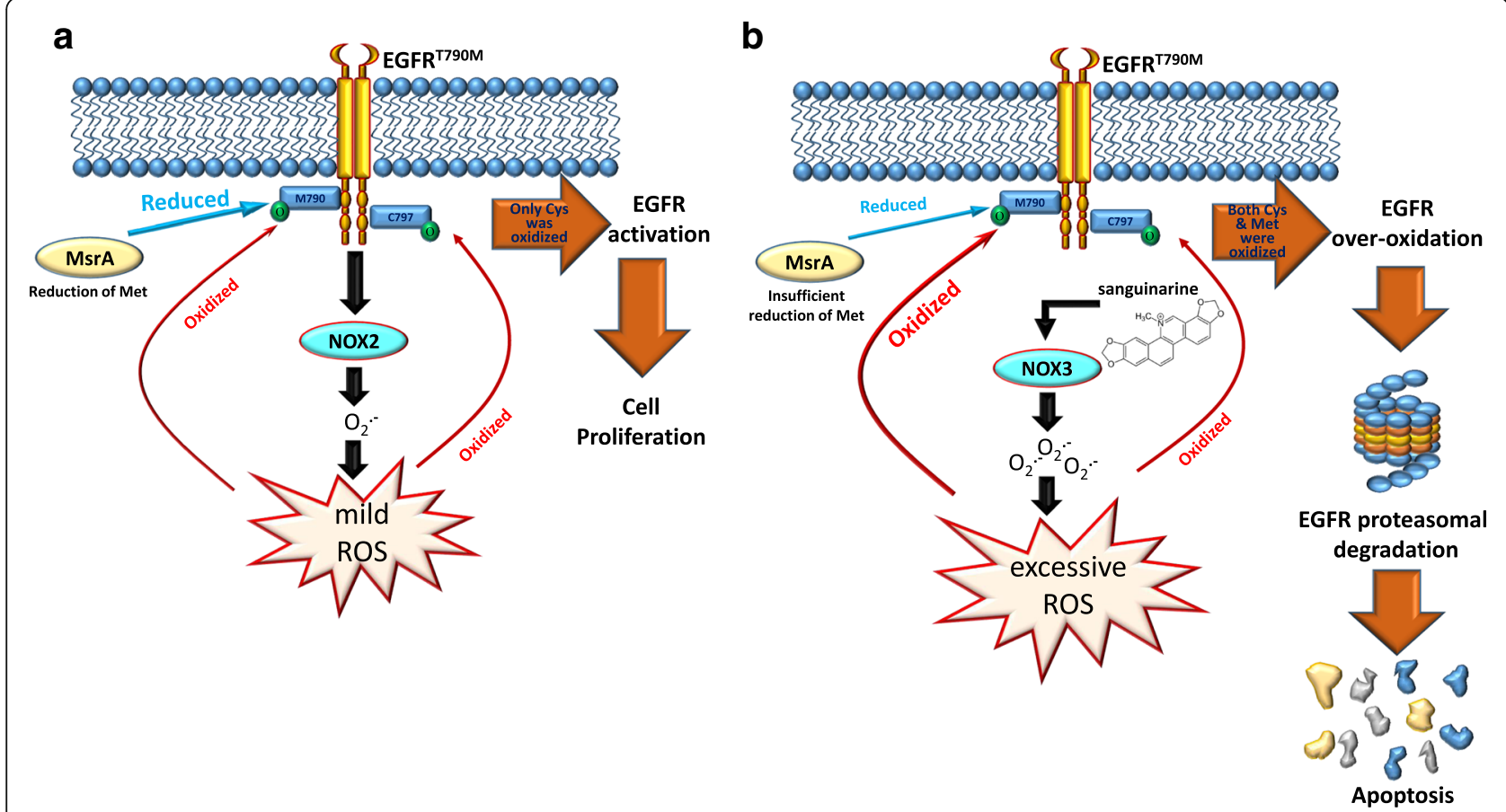

Fig. 5 Different fates of epidermal growth factor (EGF)-EGF receptor (EGFR) harboring the T790 M mutation in basal and excessive reactive oxygen species (ROS) conditions. a In the basal condition, the EGFR T790 M mutant activates NADPH oxidase 2 (NOX2) to produce ROS, and further oxidizes cysteine (Cys)797 of the EGFR, resulting in mild oxidation of methionine (Met)790. In this condition, basal activity of Met reductase A (MsrA) is fully responsible for reducing the oxidized form of Met790 on the EGFR to the reduced form and protects it from degradation, resulting in cell survival. $\mathbf{b}$ Under a condition of sanguinarine-mediated ROS overproduction, a reduction-oxidation reaction (redox) imbalance is induced by activating NOX3 to cause oxidation and depletion of NADPH, resulting in MsrA inactivation and loss of the ability to reduce the oxidized form of Met790 on the EGFR. Excessive amounts of ROS can further induce overoxidation of Met790 on the EGFR and ultimately induce EGFR degradation and cell apoptosis

of PTPs and/or specific Cys residues of the EGFR induce the EGFR-regulated signaling pathway by mild levels of ROS [64, 67]. On the contrary, higher ROS levels can trigger overoxidation of the Met residue of EGFR $^{\mathrm{T} 790 \mathrm{M}}$ and shut down the EGFR downstream survival pathway [11]. Therefore, modulating ROS levels in cancers may be a feasible therapeutic approach for cancer treatment and prevention. Although there are some studies which show that antioxidants can be used for cancer treatment $[116,117]$, recent reports indicate that using antioxidants in clinical trials might be associated with increased cancer incidences and a reduced efficacy of chemotherapy [115]. According to recent research, inhibiting metabolic pathways or ROS-scavenging mechanisms in the tumor itself, followed by treatment with pro-oxidizing agents such as chemotherapeutic drugs, represents alternative and promising therapeutic options for tumors characterized by resistance to treatment [118]. However, there are also some undesired side effects including cardiotoxicity and nephrotoxicity associated with this therapeutic strategy, and novel ROS modulators with a safer therapeutic profile should be further developed.

\section{Abbreviations}

Ang: angiopoietin; ASK1: apoptosis signal-regulating kinase 1; CDK: cyclindependent kinase; COX: cyclooxygenase; Cys: cysteine; DUOX: dual oxidase; EC: endothelial cell; EGFR: epidermal growth factor receptor; ERK: extracellular signal-regulated kinase; ETC: electron transport chain; FOXO1: Forkhead box protein O1; Grb2: growth factor receptor-bound protein 2; HIF: hypoxiainducible factor; MAPK: mitogen-activated protein kinase; MDR: multidrug resistance; Met: methionine; MMP: matrix metalloproteinase;

MsrA: methionine reductase A; mTOR: mammalian target of rapamycin; NOS: nitric oxide synthase; NOX: NADPH oxidase; NRF2: nuclear

factor-erythroid 2-related factor 2; NSCLC: non-small cell lung cancer; PAl: plasminogen activator inhibitor; PDGF: platelet-derived growth factor; P-gp: P-glycoprotein; PI3K: phosphatidylinositol-3 kinase; PTEN: phosphatase and tensin homolog; PTP: protein tyrosine phosphatase; Ref: redox factor; RNS: reactive nitrogen species; ROS: reactive oxygen species; Ser: serine; SHC: Src homology 2 domain-containing; SOD: superoxide dismutase; STAT: signal transducer and activator of transcription; Thr: threonine; TIC: tumor-initiating cell; TKI: tyrosine kinase inhibitor; UPA: urokinase plasminogen activator; VEGF: vascular endothelial growth factor

\section{Acknowledgements}

Not applicable.

\section{Funding}

This study was supported by grant 106TMU-WFH-13 from Wan Fang Hospital, Taipei Medical University (to J.-H. Chang and M.-H. Chien).

Availability of data and materials Not applicable. 


\section{Authors' contributions}

MSW was responsible for collecting data and drafting the first copy. JHC and $\mathrm{MHC}$ were responsible for searching the literature and correcting the manuscript. WYH, YCY, and WRX were responsible for drawing the schematics and overall critical revision of the entire manuscript. All authors read and approved the final manuscript.

\section{Ethics approval and consent to participate}

Not applicable.

\section{Consent for publication}

Not applicable.

\section{Competing interests}

The authors declare that they have no competing interests.

\section{Publisher's Note}

Springer Nature remains neutral with regard to jurisdictional claims in published maps and institutional affiliations.

\section{Author details}

'Department of Nutritional Science, Fu Jen Catholic University, New Taipei City, Taiwan. ${ }^{2}$ Department of Internal Medicine, School of Medicine, College of Medicine, Taipei Medical University, Taipei, Taiwan. ${ }^{3}$ Division of Pulmonary Medicine, Department of Internal Medicine, Wan Fang Hospital, Taipei Medical University, Taipei, Taiwan. ${ }^{4}$ Graduate Institute of Clinical Medicine, College of Medicine, Taipei Medical University, 250 Wu-Hsing Street, Taipei 11031, Taiwan. ${ }^{5}$ Genomics Research Center, Academia Sinica, Taipei, Taiwan. ${ }^{6}$ Department of Medical Education and Research, Wan Fang Hospital, Taipe Medical University, Taipei, Taiwan.

\section{Received: 17 January 2018 Accepted: 7 March 2018}

\section{Published online: 16 March 2018}

\section{References}

1. Wee P, Wang Z. Epidermal growth factor receptor cell proliferation signaling pathways. Cancers (Basel). 2017;9(5):E52.

2. Tomas A, Futter CE, Eden ER. EGF receptor trafficking: consequences for signaling and cancer. Trends Cell Biol. 2014;24(1):26-34.

3. Cooper WA, Lam DC, O'Toole SA, Minna JD. Molecular biology of lung cancer. J Thorac Dis. 2013:5(Suppl 5):S479-90.

4. Liu TC, Jin X, Wang Y, Wang K. Role of epidermal growth factor receptor in lung cancer and targeted therapies. Am J Cancer Res. 2017;7(2):187-202.

5. Davidson MR, Gazdar AF, Clarke BE. The pivotal role of pathology in the management of lung cancer. J Thorac Dis. 2013;5(Suppl 5):S463-78.

6. Gupta R, Dastane AM, Forozan F, Riley-Portuguez A, Chung F, Lopategui J, et al. Evaluation of EGFR abnormalities in patients with pulmonary adenocarcinoma: the need to test neoplasms with more than one method. Mod Pathol. 2009;22:128-33.

7. Lynch TJ, Bell DW, Sordella R, Gurubhagavatula S, Okimoto RA, Brannigan BW, et al. Activating mutations in the epidermal growth factor receptor underlying responsiveness of non-small-cell lung cancer to gefitinib. $\mathrm{N}$ Engl J Med. 2004;350(21):2129-39.

8. Kobayashi S, Boggon TJ, Dayaram T, Janne PA, Kocher O, Meyerson M, et al. EGFR mutation and resistance of non-small-cell lung cancer to gefitinib. $\mathrm{N}$ Engl J Med. 2005;352(8):786-92.

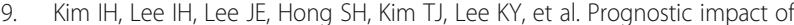
multiple Clinicopathologic risk factors and c-MET overexpression in patients who have undergone resection of stage IB non-small-cell lung Cancer. Clin Lung Cancer. 2016;17(5):e31-43.

10. Prasad S, Gupta SC, Tyagi AK. Reactive oxygen species (ROS) and cancer: role of antioxidative nutraceuticals. Cancer Lett. 2017;387:95-105.

11. Leung EL, Fan XX, Wong MP, Jiang ZH, Liu ZQ, Yao XJ, et al. Targeting tyrosine kinase inhibitor-resistant non-small cell lung Cancer by inducing epidermal growth factor receptor degradation via methionine 790 oxidation. Antioxid Redox Signal. 2016;24(5):263-79.

12. Lawless MW, O'Byrne KJ, Gray SG. Oxidative stress induced lung cancer and COPD: opportunities for epigenetic therapy. J Cell Mol Med. 2009;13(9A): 2800-21.

13. Gius D, Spitz DR. Redox signaling in cancer biology. Antioxid Redox Signal. 2006:8(7-8):1249-52
14. Halliwell B, Gutteridge JM. Role of free radicals and catalytic metal ions in human disease: an overview. Methods Enzymol. 1990;186:1-85.

15. Liou GY, Storz P. Reactive oxygen species in cancer. Free Radic Res. 2010; 44(5):479-96.

16. Kehrer JP, Klotz LO. Free radicals and related reactive species as mediators of tissue injury and disease: implications for health. Crit Rev Toxicol. 2015; 45(9):765-98.

17. Gorrini C, Harris IS, Mak TW. Modulation of oxidative stress as an anticancer strategy. Nat Rev Drug Discov. 2013;12(12):931-47.

18. Trachootham D, Alexandre J, Huang P. Targeting cancer cells by ROSmediated mechanisms: a radical therapeutic approach? Nat Rev Drug Discov. 2009;8:579-91.

19. Normanno N, De Luca A, Bianco C, Strizzi L, Mancino M, Maiello MR, et al. Epidermal growth factor receptor (EGFR) signaling in cancer. Gene. 2006:366(1):2-16

20. Schlessinger J. Ligand-induced, receptor-mediated dimerization and activation of EGF receptor. Cell. 2002;110(6):669-72.

21. Arteaga C. Targeting HER1/EGFR: a molecular approach to cancer therapy Semin Oncol. 2003:30(3 Suppl 7):3-14.

22. Hirsch FR, Varella-Garcia M, Bunn PA Jr, Di Maria MV, Veve R, Bremmes RM, et al. Epidermal growth factor receptor in non-small-cell lung carcinomas: correlation between gene copy number and protein expression and impact on prognosis. J Clin Oncol. 2003;21(20):3798-807.

23. Kosaka T, Yatabe $Y$, Endoh $H$, Kuwano $H$, Takahashi T, Mitsudomi T. Mutations of the epidermal growth factor receptor gene in lung cancer: biological and clinical implications. Cancer Res. 2004;64(24):8919-23.

24. Maik-Rachline G, Seger R. The ERK cascade inhibitors: towards overcoming resistance. Drug Resist Updat. 2016;25:1-12.

25. Camidge DR, Pao W, Sequist LV. Acquired resistance to TKls in solid tumours: learning from lung cancer. Nat Rev Clin Oncol. 2014;11(8):473-81.

26. Kang SW, Lee S, Lee EK. ROS and energy metabolism in cancer cells: alliance for fast growth. Arch Pharm Res. 2015;38(3):338-45.

27. Jones DP. Radical-free biology of oxidative stress. Am J Physiol Cell Physiol. 2008:295(4):C849-68.

28. Laurent A, Nicco C, Chereau C, Goulvestre C, Alexandre J, Alves A, et al. Controlling tumor growth by modulating endogenous production of reactive oxygen species. Cancer Res. 2005;65(3):948-56.

29. Okon IS, Zou MH. Mitochondrial ROS and cancer drug resistance: implications for therapy. Pharmacol Res. 2015;100:170-4.

30. Holmstrom KM, Finkel T. Cellular mechanisms and physiological consequences of redox-dependent signalling. Nat Rev Mol Cell Biol. 2014;15(6):411-21.

31. Wallace DC. Mitochondria and cancer. Nat Rev Cancer. 2012;12(10):685-98.

32. Tokarz P, Blasiak J. Role of mitochondria in carcinogenesis. Acta Biochim Pol. 2014;61(4):671-8.

33. Verschoor ML, Wilson LA, Singh G. Mechanisms associated with mitochondrial-generated reactive oxygen species in cancer. Can J Physiol Pharmacol. 2010:88(3):204-19.

34. Quinlan CL, Perevoshchikova IV, Hey-Mogensen M, Orr AL, Brand MD. Sites of reactive oxygen species generation by mitochondria oxidizing different substrates. Redox Biol 2013; 1: 304-312.

35. Fukai T, Ushio-Fukai M. Superoxide dismutases: role in redox signaling, vascular function, and diseases. Antioxid Redox Signal. 2011;15(6):1583-606.

36. Driessens N, Versteyhe S, Ghaddhab C, Burniat A, De Deken X, Van Sande J, et al. Hydrogen peroxide induces DNA single- and double-strand breaks in thyroid cells and is therefore a potential mutagen for this organ. Endocr Relat Cancer. 2009;16(3):845-56

37. Negrini S, Gorgoulis VG, Halazonetis TD. Genomic instability-an evolving hallmark of cancer. Nat Rev Mol Cell Biol. 2010;11(3):220-8.

38. Poole LB, Nelson KJ. Discovering mechanisms of signaling-mediated cysteine oxidation. Curr Opin Chem Biol. 2008;12(1):18-24.

39. Schwartz PA, Kuzmic P, Solowiej J, Bergqvist S, Bolanos B, Almaden C, et al. Covalent EGFR inhibitor analysis reveals importance of reversible interactions to potency and mechanisms of drug resistance. Proc Natl Acad Sci U S A. 2014:111(1):173-8

40. Truong TH, Ung PM, Palde PB, Paulsen CE, Schlessinger A, Carroll KS Molecular basis for redox activation of epidermal growth factor receptor kinase. Cell Chem Biol. 2016;23(7):837-48.

41. Heppner DE, van der Vliet A. Redox-dependent regulation of epidermal growth factor receptor signaling. Redox Biol. 2016:8:24-7.

42. Yu CX, Li S, Whorton AR. Redox regulation of PTEN by S-nitrosothiols. Mol Pharmacol. 2005;68(3):847-54. 
43. Lim JM, Lee KS, Woo HA, Kang D, Rhee SG. Control of the pericentrosomal H2O2 level by peroxiredoxin I is critical for mitotic progression. J Cell Biol. 2015;210(1):23-33.

44. Ostman A, Frijhoff J, Sandin A, Bohmer FD. Regulation of protein tyrosine phosphatases by reversible oxidation. J Biochem. 2011;150(4):345-56.

45. Qin Z, Robichaud P, He T, Fisher GJ, Voorhees JJ, Quan T. Oxidant exposure induces cysteine-rich protein 61 (CCN1) via c-Jun/AP-1 to reduce collagen expression in human dermal fibroblasts. PLoS One. 2014;9(12):e115402.

46. Ushio-Fukai M, Nakamura Y. Reactive oxygen species and angiogenesis: NADPH oxidase as target for cancer therapy. Cancer Lett. 2008;266(1):37-52.

47. Bedard K, Krause KH. The NOX family of ROS-generating NADPH oxidases: physiology and pathophysiology. Physiol Rev. 2007;87(1):245-313.

48. Meitzler JL, Antony S, Wu Y, Juhasz A, Liu H, Jiang G, et al. NADPH oxidases: a perspective on reactive oxygen species production in tumor biology. Antioxid Redox Signal. 2014;20(17):2873-89.

49. Lassegue B, San Martin A, Griendling KK. Biochemistry, physiology, and pathophysiology of NADPH oxidases in the cardiovascular system. Circ Res. 2012;110(10):1364-90.

50. Speed N, Blair IA. Cyclooxygenase- and lipoxygenase-mediated DNA damage. Cancer Metastasis Rev. 2011;30(3-4):437-47.

51. Nguyen Dinh Cat A, Montezano AC, Burger D, Touyz RM. Angiotensin II, NADPH oxidase, and redox signaling in the vasculature. Antioxid Redox Signal. 2013;19(10):1110-20.

52. Lassegue B, Sorescu D, Szocs K, Yin Q, Akers M, Zhang Y, et al. Novel gp91(phox) homologues in vascular smooth muscle cells : nox1 mediates angiotensin II-induced superoxide formation and redox-sensitive signaling pathways. Circ Res. 2001;88(9):888-94.

53. Katsuyama M, Fan C, Yabe-Nishimura C. NADPH oxidase is involved in prostaglandin F2alpha-induced hypertrophy of vascular smooth muscle cells: induction of NOX1 by PGF2alpha. J Biol Chem. 2002;277(16):13438-42.

54. Wang $\mathrm{H}$, Hartnett ME. Roles of nicotinamide adenine dinucleotide phosphate (NADPH) oxidase in angiogenesis: isoform-specific effects. Antioxidants (Basel). 2017:6(2):E40.

55. Zhang C, Lan T, Hou J, Li J, Fang R, Yang Z, et al. NOX4 promotes non-small cell lung cancer cell proliferation and metastasis through positive feedback regulation of PI3K/Akt signaling. Oncotarget. 2014;5(12):4392-405.

56. Govindarajan B, Sligh JE, Vincent BJ, Li M, Canter JA, Nickoloff BJ, et al. Overexpression of Akt converts radial growth melanoma to vertical growth melanoma. J Clin Invest. 2007;117(3):719-29.

57. Brar SS, Corbin Z, Kennedy TP, Hemendinger R, Thornton L, Bommarius B, et al. NOX5 NAD(P)H oxidase regulates growth and apoptosis in DU 145 prostate cancer cells. Am J Physiol Cell Physiol. 2003;285(2):C353-69.

58. Han M, Zhang T, Yang L, Wang Z, Ruan J, Chang X. Association between $\mathrm{NADPH}$ oxidase (NOX) and lung cancer: a systematic review and metaanalysis. J Thorac Dis. 2016;8(7):1704-11.

59. Arbiser JL, Petros J, Klafter R, Govindajaran B, McLaughlin ER, Brown LF, et al. Reactive oxygen generated by Nox1 triggers the angiogenic switch. Proc Natl Acad Sci U S A. 2002;99(2):715-20.

60. Griendling KK, Sorescu D, Ushio-Fukai M. NAD(P)H oxidase: role in cardiovascular biology and disease. Circ Res. 2000;86(5):494-501.

61. Diebold I, Petry A, Sabrane K, Djordjevic T, Hess J, Gorlach A. The HIF1 target gene NOX2 promotes angiogenesis through urotensin-II. J Cell Sci. 2012;125(Pt 4):956-64.

62. Colavitti R, Pani G, Bedogni B, Anzevino R, Borrello S, Waltenberger J, et al. Reactive oxygen species as downstream mediators of angiogenic signaling by vascular endothelial growth factor receptor-2/KDR. J Biol Chem. 2002; 277(5):3101-8

63. Gamou S, Shimizu N. Hydrogen peroxide preferentially enhances the tyrosine phosphorylation of epidermal growth factor receptor. FEBS Lett. 1995;357(2):161-4.

64. Bae YS, Kang SW, Seo MS, Baines IC, Tekle E, Chock PB, et al. Epidermal growth factor (EGF)-induced generation of hydrogen peroxide. Role in EGF receptor-mediated tyrosine phosphorylation. J Biol Chem. 1997; 272(1):217-21.

65. Zhang J, Yang PL, Gray NS. Targeting cancer with small molecule kinase inhibitors. Nat Rev Cancer. 2009;9(1):28-39.

66. Paulsen CE, Truong TH, Garcia FJ, Homann A, Gupta V, Leonard SE, et al. Peroxide-dependent sulfenylation of the EGFR catalytic site enhances kinase activity. Nat Chem Biol. 2011;8(1):57-64.

67. Truong TH, Carroll KS. Redox regulation of epidermal growth factor receptor signaling through cysteine oxidation. Biochemistry. 2012;51(50):9954-65.
68. Goldkorn T, Balaban N, Matsukuma K, Chea V, Gould R, Last J, et al. EGFreceptor phosphorylation and signaling are targeted by $\mathrm{H} 2 \mathrm{O} 2$ redox stress. Am J Respir Cell Mol Biol. 1998;19(5):786-98.

69. D'Autreaux B, Toledano MB. ROS as signalling molecules: mechanisms that generate specificity in ROS homeostasis. Nat Rev Mol Cell Biol. 2007:8(10):813-24.

70. Rao GN. Hydrogen peroxide induces complex formation of SHC-Grb2-SOS with receptor tyrosine kinase and activates Ras and extracellular signalregulated protein kinases group of mitogen-activated protein kinases. Oncogene. 1996;13(4):713-9.

71. Heppner DE, Hristova M, Dustin CM, Danyal K, Habibovic A, van der Vliet A. The NADPH oxidases DUOX1 and NOX2 play distinct roles in redox regulation of epidermal growth factor receptor signaling. J Biol Chem. 2016;291(44):23282-93.

72. Sasaoka T, Langlois WJ, Leitner JW, Draznin B, Olefsky JM. The signaling pathway coupling epidermal growth factor receptors to activation of p21ras. J Biol Chem. 1994;269(51):32621-5.

73. Kyriakis JM, App H, Zhang XF, Banerjee P, Brautigan DL, Rapp UR, et al. Raf-1 activates MAP kinase-kinase. Nature. 1992;358(6385):417-21.

74. Morrison DK. MAP kinase pathways. Cold Spring Harb Perspect Biol. 2012; 4(11):a011254

75. Lewis TS, Shapiro PS, Ahn NG. Signal transduction through MAP kinase cascades. Adv Cancer Res. 1998;74:49-139.

76. Franke TF, Kaplan DR, Cantley LC, Toker A. Direct regulation of the Akt proto-oncogene product by phosphatidylinositol-3,4-bisphosphate. Science. 1997;275(5300):665-8

77. Salmena L, Carracedo A, Pandolfi PP. Tenets of PTEN tumor suppression. Cell. 2008;133(3):403-14

78. Park HS, Lee SH, Park D, Lee JS, Ryu SH, Lee WJ, et al. Sequential activation of phosphatidylinositol 3-kinase, beta pix, Rac1, and Nox1 in growth factorinduced production of H2O2. Mol Cell Biol. 2004;24(10):4384-94.

79. Kwon J, Lee SR, Yang KS, Ahn Y, Kim YJ, Stadtman ER, et al. Reversible oxidation and inactivation of the tumor suppressor PTEN in cells stimulated with peptide growth factors. Proc Natl Acad Sci U S A. 2004;101(47):16419-24.

80. Lee CU, Hahne G, Hanske J, Bange T, Bier D, Rademacher C, et al. Redox modulation of PTEN phosphatase activity by hydrogen peroxide and Bisperoxidovanadium complexes. Angew Chem Int Ed Engl. 2015;54(46): 13796-800.

81. Fumarola C, Bonelli MA, Petronini PG, Alfieri RR. Targeting PI3K/AKT/ mTOR pathway in non small cell lung cancer. Biochem Pharmacol. 2014;90(3):197-207.

82. Huang X, Begley M, Morgenstern KA, Gu Y, Rose P, Zhao H, et al. Crystal structure of an inactive Akt2 kinase domain. Structure. 2003;11(1):21-30.

83. Murata H, Ihara $Y$, Nakamura H, Yodoi J, Sumikawa K, Kondo T. Glutaredoxin exerts an antiapoptotic effect by regulating the redox state of Akt. J Biol Chem. 2003;278(50):50226-33.

84. Filosto S, Khan EM, Tognon E, Becker C, Ashfaq M, Ravid T, et al. EGF receptor exposed to oxidative stress acquires abnormal phosphorylation and aberrant activated conformation that impairs canonical dimerization. PLoS One. 2011;6(8):e23240.

85. Filosto $\mathrm{S}$, Becker CR, Goldkorn T. Cigarette smoke induces aberrant EGF receptor activation that mediates lung cancer development and resistance to tyrosine kinase inhibitors. Mol Cancer Ther. 2012;11(4):795-804.

86. Zhang L, Li J, Hu J, Li D, Wang X, Zhang R, et al. Cigarette smoke extract induces EGFR-TKI resistance via promoting EGFR signaling pathway and ROS generation in NSCLC cell lines. Lung Cancer. 2017:109:109-16.

87. Giordano CR, Mueller KL, Terlecky LJ, Krentz KA, Bollig-Fischer A, Terlecky SR, et al. A targeted enzyme approach to sensitization of tyrosine kinase inhibitor-resistant breast cancer cells. Exp Cell Res. 2012;318(16):2014-21.

88. Uramoto H, Iwata T, Onitsuka T, Shimokawa H, Hanagiri T, Oyama T. Epithelial-mesenchymal transition in EGFR-TKI acquired resistant lung adenocarcinoma. Anticancer Res. 2010;30(7):2513-7.

89. Li D, Zhang L, Zhou J, Chen H. Cigarette smoke extract exposure induces EGFR-TKI resistance in EGFR-mutated NSCLC via mediating Src activation and EMT. Lung Cancer. 2016;93:35-42.

90. Remon J, Moran T, Majem M, Reguart N, Dalmau E, Marquez-Medina D, et al. Acquired resistance to epidermal growth factor receptor tyrosine kinase inhibitors in EGFR-mutant non-small cell lung cancer: a new era begins. Cancer Treat Rev. 2014;40(1):93-101.

91. Zhang H, Liu H, Borok Z, Davies KJ, Ursini F, Forman HJ. Cigarette smoke extract stimulates epithelial-mesenchymal transition through Src activation. Free Radic Biol Med. 2012;52(8):1437-42. 
92. Nishikawa M. Reactive oxygen species in tumor metastasis. Cancer Lett. 2008;266(1):53-9.

93. Sayin VI, Ibrahim MX, Larsson E, Nilsson JA, Lindahl P, Bergo MO. Antioxidants accelerate lung cancer progression in mice. Sci Transl Med. 2014;6(221):221ra15.

94. Okon IS, Coughlan KA, Zhang M, Wang Q, Zou MH. Gefitinib-mediated reactive oxygen specie (ROS) instigates mitochondrial dysfunction and drug resistance in lung cancer cells. J Biol Chem. 2015;290(14):9101-10.

95. Blot WJ, Li JY, Taylor PR, Guo W, Dawsey S, Wang GQ, et al. Nutrition intervention trials in Linxian, China: supplementation with specific vitamin/ mineral combinations, cancer incidence, and disease-specific mortality in the general population. J Natl Cancer Inst. 1993;85(18):1483-92.

96. Stefani ED, Boffetta P, Deneo-Pellegrini H, Mendilaharsu M, Carzoglio JC, Ronco A, et al. Dietary antioxidants and lung cancer risk: a case-control study in Uruguay. Nutr Cancer. 1999;34(1):100-10.

97. Wright ME, Virtamo J, Hartman AM, Pietinen P, Edwards BK, Taylor PR, et al. Effects of alpha-tocopherol and beta-carotene supplementation on upper aerodigestive tract cancers in a large, randomized controlled trial. Cancer. 2007;109(5):891-8.

98. Lee IM, Cook NR, Gaziano JM, Gordon D, Ridker PM, Manson JE, et al. Vitamin $\mathrm{E}$ in the primary prevention of cardiovascular disease and cancer: the Women's health study: a randomized controlled trial. JAMA. 2005;294(1):56-65.

99. Rautalahti MT, Virtamo JR, Taylor PR, Heinonen OP, Albanes D, Haukka JK, et al. The effects of supplementation with alpha-tocopherol and betacarotene on the incidence and mortality of carcinoma of the pancreas in a randomized, controlled trial. Cancer. 1999;86(1):37-42.

100. Alpha-Tocopherol, Beta Carotene Cancer Prevention Study Group. The effect of vitamin $E$ and beta carotene on the incidence of lung cancer and other cancers in male smokers. N Engl J Med. 1994;330(15):1029-1035.

101. Neuhouser ML, Barnett MJ, Kristal AR, Ambrosone CB, King IB, Thornquist M, et al. Dietary supplement use and prostate cancer risk in the carotene and retinol efficacy trial. Cancer Epidemiol Biomark Prev. 2009;18(8):2202-6.

102. Bairati I, Meyer F, Gelinas M, Fortin A, Nabid A, Brochet F, et al. A randomized trial of antioxidant vitamins to prevent second primary cancers in head and neck cancer patients. J Natl Cancer Inst. 2005;97(7):481-8.

103. Weinberg SE, Chandel NS. Targeting mitochondria metabolism for cancer therapy. Nat Chem Biol. 2015;11(1):9-15

104. Hashida S, Yamamoto H, Shien K, Miyoshi Y, Ohtsuka T, Suzawa K, et al. Acquisition of cancer stem cell-like properties in non-small cell lung cancer with acquired resistance to afatinib. Cancer Sci. 2015;106(10):1377-84.

105. Kim HM, Haraguchi N, Ishii H, Ohkuma M, Okano M, Mimori K, et al. Increased CD13 expression reduces reactive oxygen species, promoting survival of liver cancer stem cells via an epithelial-mesenchymal transitionlike phenomenon. Ann Surg Oncol. 2012;19(Suppl 3):S539-48.

106. Diehn M, Cho RW, Lobo NA, Kalisky T, Dorie MJ, Kulp AN, et al. Association of reactive oxygen species levels and radioresistance in cancer stem cells. Nature. 2009;458(7239):780-3.

107. Ryoo IG, Lee SH, Kwak MK. Redox modulating NRF2: a potential mediator of Cancer stem cell resistance. Oxidative Med Cell Longev. 2016;2016:2428153.

108. Wartenberg M, Richter M, Datchev A, Gunther S, Milosevic N, Bekhite MM, et al. Glycolytic pyruvate regulates P-glycoprotein expression in multicellular tumor spheroids via modulation of the intracellular redox state. J Cell Biochem. 2010;109(2):434-46.

109. Wartenberg M, Ling FC, Muschen M, Klein F, Acker H, Gassmann M, et al. Regulation of the multidrug resistance transporter P-glycoprotein in multicellular tumor spheroids by hypoxia-inducible factor (HIF-1) and reactive oxygen species. FASEB J. 2003;17(3):503-5.

110. Dharmaraja AT. Role of reactive oxygen species (ROS) in therapeutics and drug resistance in Cancer and bacteria. J Med Chem. 2017;60(8):3221-40.

111. Sequist LV, Waltman BA, Dias-Santagata D, Digumarthy $S$, Turke AB, Fidias $P$, et al. Genotypic and histological evolution of lung cancers acquiring resistance to EGFR inhibitors. Sci Transl Med. 2011:3(75):75ra26.

112. Goldman EH, Chen L, Fu H. Activation of apoptosis signal-regulating kinase 1 by reactive oxygen species through dephosphorylation at serine 967 and 14-3-3 dissociation. J Biol Chem. 2004;279(11):10442-9.

113. Jiang $Y$, Wang $X, H u$ D. Furanodienone induces G0/G1 arrest and causes apoptosis via the ROS/MAPKs-mediated caspase-dependent pathway in human colorectal cancer cells: a study in vitro and in vivo. Cell Death Dis. 2017;8(5):e2815
114. Lee HY, Parkinson El, Granchi C, Paterni I, Panigrahy D, Seth P, et al. Reactive oxygen species synergize to potently and selectively induce Cancer cell death. ACS Chem Biol. 2017;12(5):1416-24.

115. Acharya A, Das I, Chandhok D, Saha T. Redox regulation in cancer: a double-edged sword with therapeutic potential. Oxidative Med Cell Longev. 2010;3(1):23-34.

116. Prasad KN, Cole WC. Antioxidants in cancer therapy. J Clin Oncol. 2006;24(6): e8-9. author reply e10

117. Chikara S, Nagaprashantha LD, Singhal J, Horne D, Awasthi S, Singhal SS Oxidative stress and dietary phytochemicals: role in cancer chemoprevention and treatment. Cancer Lett. 2018:413:122-34.

118. Panieri E, Santoro MM. ROS homeostasis and metabolism: a dangerous liason in cancer cells. Cell Death Dis. 2016;7(6):e2253.

\section{Submit your next manuscript to BioMed Central and we will help you at every step:}

- We accept pre-submission inquiries

- Our selector tool helps you to find the most relevant journal

- We provide round the clock customer support

- Convenient online submission

- Thorough peer review

- Inclusion in PubMed and all major indexing services

- Maximum visibility for your research

Submit your manuscript at www.biomedcentral.com/submit

) Biomed Central 